\title{
Investigating the relationships among the knowledge sharing system indices in the educational organizations
}

\author{
Houshang Taghizadeh* and Mostafa Ziyaei Hajipirlu
}

Department of Management, Tabriz Branch, Islamic Azad University, Tabriz, Iran

\begin{tabular}{l}
\hline C H R O N I C L E \\
\hline Article history: \\
Received October 29, 2014 \\
Received in revised format: \\
March 2, 2015 \\
Accepted April 22, 2015 \\
Available online \\
April 25 2015 \\
\hline Keywords: \\
Knowledge sharing \\
Systemic approach \\
Knowledge management \\
Lessons learned systems \\
Educational organizations
\end{tabular}

\section{Introduction}

Nowadays, knowledge management (KM) and appropriate knowledge system (KS) are among the most important and vital factors in organizations. In other words, the organizations that develop and improve their invisible and spiritual capitals would turn out to be more successful at the times of changes. Today, in the era of information (after 1950), knowledge and information are considered as the main sources of gaining wealth and power, the powerful and wealthy people are those who are more knowledgeable and possess more information. Another feature of modern organizations is over-accumulation of information. The increase in the amount of information in organizations and the necessity to use it in organizational decisions have led to the advent of a KM. In educational settings, universities and educational organizations, new information is created by processing the available information. Therefore, identifying the indices that influence on the collection, accumulation and storage of

\footnotetext{
* Corresponding author

E-mail address: taghizadeh@iaut.ac.ir (H. Taghizadeh)

(c) 2015 Growing Science Ltd. All rights reserved. doi: 10.5267/j.dsl.2015.4.006
} 
information, the identification of these factors, the storage of shared knowledge, and attempting to create a structure for more effective management of knowledge and collaborative learning are the main challenges that policy-making managers encounter.

$\mathrm{KS}$, as a complicated but value-creating activity, is the basis for the establishment of KM strategies in organizations. Studies indicate that having access to an efficient KSS and effective KM guarantees organizational survival and development. Therefore, the identification and strengthening of the Knowledge Sharing indices are vital and important for gaining competitive advantage (Riege, 2005). Using the factors and indices that have so far been identified as factors affecting knowledge sharing, this study attempts to clarify the interrelationships among system indices by investigating the type and intensity of direct/indirect influential and influenced relationships. It, further, proposes a model to measure the intensity of indirect relationships among the indices.

\subsection{KM and KS Systems}

KM refers to any type of activity employed to promote the maximum exploitation of knowledge sources. In other words, KM is an exclusive, organized and systematic process applied for the purpose of gaining, organizing, maintaining, applying, distributing and recreating the explicit and implicit knowledge of the employees in order to improve organizational performance and to establish values. $\mathrm{KM}$ is a systematic managerial strategy that blends the information technology and organizational process. Indeed, it is a managerial activity that develops, transfers, sends, stores and applies knowledge. It, furthermore, provides an organization with real information for the purpose of reacting and making accurate decisions in order to achieve organizational goals (Hung et al., 2005).

The concept of KM originally was originally applied at individual and personal levels, today, however, it is used at organizational levels as well. Owing to the dramatic developments in knowledge and technology and creation of discipline and coherence in gaining, sharing, and applying knowledge at organizational levels, KM has gained a prime importance (Becerra \& Sabherwal, 2010). In the business environment, the management of knowledge is considered as an important factor in gaining competitive advantage (Hedlund \& Nonaka, 1996). To achieve competitive advantage, organizations ought to understand how to manage creation, sharing and exploitation of organizational knowledge (Szulanski, 1996).

The process of sharing knowledge as one of the main factors in KM system can be explained in the following way: by sharing knowledge on the part of a particular person, we mean that an individual guides another person via using his/her knowledge, attitudes and thoughts to help him/her to look at his/her situation from a better perspective (McDermott, 1999). Moreover, the individual who shares his/her knowledge ought to know the function of the shared knowledge and its application as well as the requirements and necessary information gaps of the receiver of the information. A KS system (KSS) is a system that attempts to reach appropriate organization and distribution of knowledge. Moreover, KSS gives organization members with a definition of organizational learning from a supportive perspective. It also determines the procedures to share and reuse knowledge (Becerra \& Sabherwal, 2010).

According to (Abecker et al., 1998), the primary function of KSS is "to enhance the organization's competitiveness by improving the way it manages its knowledge”. Looking at KSS from the humanistic point of view, which is the most important element in any system, we determine two groups: knowledge seekers and knowledge owners (Becerra \& Sabherwal, 2010). In this view, KSS can be explained as a system, which helps members of an organization acquire tacit and explicit knowledge from each other. It may also be considered as a knowledge market. As a market, which needs sufficient liquidity to guarantee a fair exchange of products, KSS has to attract an efficient amount of knowledge seekers and knowledge owners (Dignum, 2002). In a KSS, knowledge owners might: 1) wish to share their 
knowledge with a controllable and trustable group, 2) determine when to share and decide on the necessary conditions for sharing, and 3) look for a fair exchange or reward for sharing their knowledge. By the same token, knowledge seekers may: 1) not be aware of all the possibilities for sharing, thus the knowledge repository will basically help them through search and rank and 2) decide on the necessary conditions for knowledge acquisition (Becerra \& Sabherwal, 2010). KSSs are classified based on their attributes. These specific types of KSSs include: 1) Incident report databases (IRD), 2) Alert systems (AS), 3) Best practices databases (BPD), 4) Lessons learned systems (LLS) and 5) Expertise locator systems (ELS) (Becerra \& Sabherwal, 2010). To be brief and to pursue the main objectives of the present study, we will investigate only LLs, and other systems will not be discussed here.

\subsection{Lessons Learned Systems (LLS)}

The most commonly applied KSSs are probably those implemented in ELS learning/teaching agencies. In addition to the economies whose competitive advantages depend on knowledge, the use of Lessons Learned Systems (LLS) is essential (Becerra \& Sabherwal, 2010). Today, many commercial as well as governmental organizations keep some sort of LLS. Future LLSs are expected to include advanced intelligent technologies, which would alert the decision maker of the available support in the form of explicit lessons in the context of decision-making process (Becerra \& Sabherwal, 2010). Moreover, LSS is widely applied in its original starting place, namely universities and educational centers.

A lesson learned is the knowledge or understanding gained by an experience (Becerra \& Sabherwal, 2010). A lesson must be significant since it has a real impact on operations. It is necessary because it is factual and technical and it is applicable since it identifies a specific design, process, or decision that reduces or eliminates the potential for failures and mishaps, or reinforces a positive result (Secchi et al., 1999). According to Weber et al. (2001), the primary objective of LLS is "to capture and provide lessons that can benefit employees who encounter situations that closely resemble a previous experience in a similar situation". In other words, the primary purpose of LLS is to support organizational processes Fig.1 explains the essential tasks of LLS as collecting, verifying, storing, disseminating and reusing.

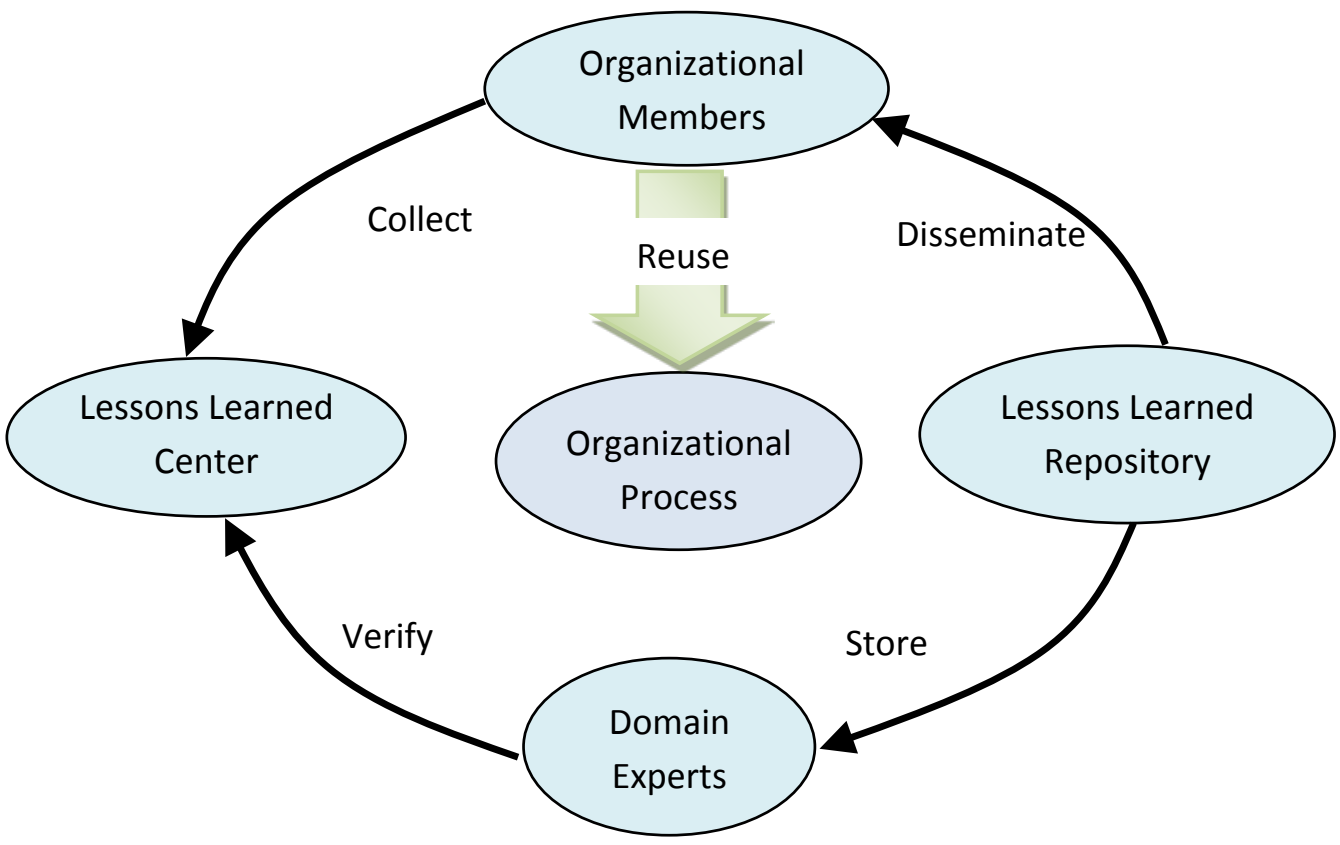

Fig.1. Lesson Learned Process (Weber et al., 2001)

To strengthen the humanistic and managerial-functional dimensions of LLS, during the first stage, the effective indices on LSS have to be determined. It would be helpful in proposing the strategies for 
improving the present state and heading towards the desirable state. So far, some of the factors and indices influencing LLS have been identified for the knowledge management cycle. The above mentioned indices and their definitions are illustrated in Table 1 (to be brief, the abbreviation for each index is provided in the same line).

\section{Table 1}

Indices for sharing knowledge and their definitions (Manyan \& Mira, 2011)

\begin{tabular}{|c|c|c|}
\hline Sign & Factor & Definition \\
\hline A & Perception & $\begin{array}{l}\text { The scope of individual's understanding of the social value and the importance of } \\
\text { learning and sharing knowledge }\end{array}$ \\
\hline B & Trust & An individual's reliance on other people and their information \\
\hline $\mathrm{C}$ & $\begin{array}{l}\text { Openness in } \\
\text { Communication }\end{array}$ & $\begin{array}{l}\text { Openness, wide distribution and ease of communication among the system } \\
\text { members }\end{array}$ \\
\hline $\mathrm{D}$ & Collaboration & $\begin{array}{l}\text { Willingness for group work to achieve the goals and the existence of the culture of } \\
\text { cooperation in line with the purpose of sharing knowledge }\end{array}$ \\
\hline $\mathrm{E}$ & Reward systems & $\begin{array}{l}\text { A system for assessing the shared knowledge and giving appropriate and suitable } \\
\text { rewards to the people involved and enjoying the support of high ranking managers } \\
\text { in the organization. }\end{array}$ \\
\hline $\mathrm{F}$ & Communication Channels & $\begin{array}{l}\text { Communication channels based on information technology and communications in } \\
\text { order to collect and share knowledge }\end{array}$ \\
\hline G & $\begin{array}{l}\text { Knowledge Sharing Self- } \\
\text { Efficiency }\end{array}$ & People's ability to sharing knowledge or values \\
\hline $\mathrm{H}$ & $\begin{array}{l}\text { Perceived Relative } \\
\text { Advantage }\end{array}$ & $\begin{array}{l}\text { The extent of an individual's understanding of the advantages of the shared } \\
\text { knowledge }\end{array}$ \\
\hline I & Competition & $\begin{array}{l}\text { Individual's resistance against knowledge sharing activities to achieve the goals } \\
\text { and rewards }\end{array}$ \\
\hline $\mathrm{J}$ & Face to face interactions & $\begin{array}{l}\text { The effect of individuals' face-to-face interactions in sharing effective and useful } \\
\text { knowledge }\end{array}$ \\
\hline
\end{tabular}

\section{Background}

Each of the factors and indices presented in Table 1 has been confirmed by the researchers working in this area. Table 2 presents the list of the factors and people who have already carried out studies in this area.

\section{Table 2}

Studies conducted on the identification of the indices of knowledge sharing

\begin{tabular}{|c|c|}
\hline Factor & Researchers that have been confirmed the factor \\
\hline Perception & Kim \& Ju, 2008; Yang, 2009; Manian \& Mira, 2011; Wang \& Noe, 2010 \\
\hline Trust & $\begin{array}{l}\text { Huang, 2009; Lin, Hung \& Chen, 2009; Gruber \& Duxbury, 2001; Hsu et al, 2006; Kim } \\
\text { \& Ju, 2008; Manian \& Mira, 2011; Wang \& Noe, 2010; Islam et al., } 2011\end{array}$ \\
\hline $\begin{array}{l}\text { Openness in } \\
\text { Communication }\end{array}$ & $\begin{array}{l}\text { Yu \& Liu, 2008; Gruber \& Duxbury, 2001; Lin, 2008; Kim \& Ju, 2008; Manian \& Mira, } \\
\text { 2011; Islam et al., } 2011\end{array}$ \\
\hline Collaboration & $\begin{array}{l}\text { Willem \& Buelens, 2009; Yu \& Liu, 2008; Sveiby \& Simons, 2002; Manian \& Mira, } \\
\text { 2011; Wang \& Noe, } 2010\end{array}$ \\
\hline Reward systems & $\begin{array}{l}\text { Gruber \& Duxbury, 2001; Han \& Anantantmula, 2007; Lin, 2007; Lin, 2008; Kim \& Ju, } \\
\text { 2008; Yu \& Liu, 2008; Yang, 2009; Manian \& Mira, 2011; Wang \& Noe, } 2010\end{array}$ \\
\hline Communication Channels & $\begin{array}{l}\text { Han \& Anantantmula, 2007; Kim \& Ju, 2008; Manian \& Mira, 2011; Bellifemine et al., } \\
2008\end{array}$ \\
\hline $\begin{array}{l}\text { Knowledge Sharing Self- } \\
\text { Efficiency }\end{array}$ & $\begin{array}{l}\text { Gruber \& Duxbury, 2001; Hsu et al., 2006; Lin, 2008; Wang \& Noe, 2010; Babalhavaeji } \\
\text { \& Jafarzadeh Kermani, } 2011\end{array}$ \\
\hline $\begin{array}{l}\text { Perceived Relative } \\
\text { Advantage }\end{array}$ & Lin, Hung \& Chen, 2009; Yu \& Liu, 2008; Kim \& Ju, 2008; Wang \& Noe, 2010 \\
\hline Competition & Willem \& Buelens, 2009; Han \& Anantantmula, 2007; Lin, 2007; Kim \& Ju, 2008 \\
\hline Face to face interactions & $\begin{array}{l}\text { Yu \& Liu, 2008; Hsu et al, 2006; Gruber \& Duxbury, 2001; Willem \& Buelens, 2009; } \\
\text { Wang \& Noe, } 2010\end{array}$ \\
\hline
\end{tabular}


Table 2 shows the nature of the research and due to the comprehensibility of the present research and the closeness of its population to the population of the reviewed study (Manyan \& Mira, 2011), the indices studied by Manyan and Mira (2011) will be taken into account as the variables in the current study (Table 1).

\section{Methodology}

Since the results of the present research can be used in taking decisions on the increasing rate of the effect of knowledge management and knowledge sharing programs on LLSs, this is an applied research, and from the viewpoint of research procedure, it is of descriptive-analytical type. The data have been collected from two sources, the library survey and gaining the expert views of the connoisseurs. The main requirements for the experts to be considered as the connoisseurs in the field were as follows: having over 15 years of technical and practical experience pertinent to the topic of the research; having adequate scientific background, i.e., having published at least 2 articles on the subject under study; and having at least 15 years of executive experience in different universities in Iran. Based on the abovementioned requirements, 36 eligible university professors were identified as the connoisseurs and were given the questionnaires for the collection of the preliminary data. A researcher-made questionnaire designed on the basis of the identified indices of LLS type knowledge sharing was used for collecting the data. The primary objective of the questionnaire was to identify the rate of interrelationships between indices with pairwise comparisons. The, validity of the questionnaire was confirmed by using content validity analysis method with the collaboration of 6 experts.

The reliability of the questionnaire was assessed by test-retest method and by distributing the questionnaires among 10 experts at two different times within a three-week interval. For this purpose, the researchers applied correlation test, and for the responses given at the first and second occasions, they calculated Spearman correlation coefficient for each component separately. The results are shown in Table 3.

\section{Table 3}

The results of spearman correlation coefficients for each Factor

\begin{tabular}{llc}
\hline Sign & Factor & Spearman Correlation Coefficient \\
\hline A & Perception & 0.825 \\
B & Trust & 0.714 \\
C & Openness in Communication & 0.710 \\
D & Collaboration & 0.858 \\
E & Reward systems & 0.706 \\
F & Communication Channels & 0.785 \\
G & Knowledge Sharing Self- Efficiency & 0.733 \\
H & Perceived Relative Advantage & 0.880 \\
I & Competition & 0.794 \\
J & Face to face interactions & 0.731 \\
\hline
\end{tabular}

Considering the correlation coefficients shown in Table 3, the values obtained for each component is higher than 0.7 , which indicates the acceptable reliability of the questionnaire.

\section{The DEMATEL Method}

The Decision Making Trial and Evaluation Laboratory (DEMATEL) is a comprehensive scientific research method, developed in 1970s by Science and Human Affairs Program at the Battelle Memorial Institute in Geneva. The method is used to solve scientific, political, economic, and other complicated problems that contain a complex array of important factors (Gabus \& Fontela, 1973). The present study analyzes the concepts and definitions employing DEMATEL. There are two purposes for using DEMATEL: 1) to increase the rigor of the authors' analysis via scientific method, and 2) to provide 
decision makers with greater confidence as they attempt to choose the most efficient ways to fortify the similar LLS functions using the type and strength of the relationships among system elements. The use of this technique contributes to a better identification and understanding of the system indices and interrelationships among them, which is very helpful in making decisions on the procedures for creating more effective and efficient systems.

The method which has been used in this research can be summarized in the following steps:

Step 1: Locating the finalized relationships between indices matrix: Suppose we have $H$ experts and $n$ factors to consider. Each expert is asked to indicate the degree to which he/ she believes a factor $i$ influences on factor $j$. These pairwise comparisons between any two factors are denoted by $a_{i j}$ and are given an integer score ranging from $0,1,2, . ., 9$ and 10, representing 'No influence (0),' 'Very Low influence (1),', ..., 'Medium influence (5),', ..., and 'Very high influence (10),' respectively. The scores by each expert will give us an $\mathrm{n} \times \mathrm{n}$ non-negative answer matrix $\boldsymbol{X}^{k}=\left[x_{i j}^{k}\right]$, with $1 \leq k \leq H$. Thus $X^{1}$, $X^{2}, \ldots, X^{H}$ are the response matrices for each of the $\mathrm{H}$ experts, and each element of $X^{k}$ is an integer denoted by $X_{i j}^{k}$. The diagonal elements of each answer matrix $X^{k}$ are all set to zero. Then, we can compute the $\mathrm{n} \times \mathrm{n}$ average matrix $\mathbf{A}$ for all expert opinions by geometric mean given in Eq. (1).

$$
X_{i j}^{\prime}=\prod_{l=1}^{k} X_{i j l}^{\frac{1}{k}}
$$

In Eq. (1), $l$ stands for the number of one decision-marker ( $\mathrm{L}^{\text {th }}$ decision marker) where $1 \leq \mathrm{L} \leq \mathrm{k}, \mathrm{K}$ is the number of decision-makers, and ( $i j)$ is the rate of the relationship of component $i$ with component $j$ which has been specified by the 1th decision-marker. According to the above explanations, the data detained from the questionnaires are gathered in Table 2 in the form of the finalized relationship matrix, which indeed is the matrix that indicates the intensity of the direct relationships of each pair of the research factors. The Finalized relationships matrix $\boldsymbol{A}=\left[a_{i j}\right]$ is also called the initial direct relation matrix; it shows the initial direct effects that each factor exerts on and receives from the other factors.

Step 2: Calculating the normalized initial direct-relation matrix. The normalized initial direct-relation matrix $\boldsymbol{D}$ is obtained by normalizing matrix $\boldsymbol{A}$ in the following way:

Let

$$
s=\max \left(\max _{1 \leq i \leq n} \sum_{j=1}^{n} a_{i j}, \max _{1 \leq j \leq n} \sum_{i=1}^{n} a_{i j}\right)
$$

Then

$$
D=\frac{A}{S}
$$

Since the sum of each row $j$ of matrix $\boldsymbol{A}$ represents the total direct impacts that factor $i$ exerts on the other factors, $\max _{1 \leq i \leq n} \sum_{j=1}^{n} a_{i j}$ represents the total direct impacts of the factor with the most direct impacts on others. Likewise, since the sum of each column $i$ of matrix $\boldsymbol{A}$ represents the total direct effects received by factor $i, \max _{1 \leq j \leq n} \sum_{i=1}^{n} a_{i j}$ represents the total direct effects received from the factor that receives the most direct effects from others. The positive scalar $s$ takes the lesser of the two as the upper bound, and the matrix $\boldsymbol{D}$ is obtained by dividing each element of $\boldsymbol{A}$ by the scalar s. Also, each element $d_{i j}$ of matrix $\boldsymbol{D}$ is between zero and less than 1 . 
Step 3: the total relation matrix calculation. A continuous decrease of the indirect effects of problems along the powers of matrix $\mathbf{D}$, e.g. $\boldsymbol{D}^{2}, \boldsymbol{D}^{3}, \ldots, \boldsymbol{D}^{\infty}$, guarantees convergent solutions to the matrix inversion similar to an absorbing Markov chain matrix: $\lim _{m \rightarrow \infty} \boldsymbol{D}^{m}=[0]_{n \times n}$ and $\lim _{m \rightarrow \infty}\left(\boldsymbol{I}+\boldsymbol{D}+\boldsymbol{D}^{2}+\boldsymbol{D}^{3}+\ldots+\boldsymbol{D}^{m}\right)=(\boldsymbol{I}-\boldsymbol{D})^{-1}$, where 0 is the $\mathrm{n} \times \mathrm{n}$ null matrix and $\mathrm{I}$ is the $\mathrm{n} \times \mathrm{n}$ identity matrix. The total relation (direct and indirect) matrix $\mathbf{T}$ is an $\mathrm{n} \times \mathrm{n}$ matrix and is defined as follows:

$$
\mathbf{T}=\left[\mathrm{t}_{\mathrm{ij}}\right] \quad \mathrm{i}, \mathrm{j}=1,2, \ldots, \mathrm{n}
$$

where

$$
\begin{aligned}
\mathbf{T} & =\mathbf{D}+\mathbf{D}^{2}+\ldots+\mathbf{D}^{\mathbf{m}}=\boldsymbol{D}+\boldsymbol{D}^{2}+\ldots+\boldsymbol{D}^{\mathrm{m}}=\mathbf{D}\left(I+\boldsymbol{D}+\boldsymbol{D}^{2}+\ldots+\boldsymbol{D}^{m-1}\right) \\
& =\boldsymbol{D}\left[\left(I+\boldsymbol{D}+\boldsymbol{D}^{2}+\ldots+\boldsymbol{D}^{m-1}\right)(1-\boldsymbol{D})\right](1-\boldsymbol{D})^{-1}=\mathbf{D}(\mathbf{I}-\mathbf{D})^{-1} \text {, as } m \rightarrow \infty
\end{aligned}
$$

We also define $\mathbf{r}$ and $\mathbf{c}$ as $n \times 1$ vectors representing the sum of rows and sum of columns of the total relation matrix $\mathbf{T}$ as follows:

$$
\begin{aligned}
& r=\sum_{j=1}^{n} t_{i j} \\
& \boldsymbol{c}=\left[c_{j}\right]_{1 \times n}^{\prime}=\left(\sum_{i=1}^{n} t_{i j}\right)_{1 \times n}^{\prime}
\end{aligned}
$$

where superscript ' denotes transpose.

Let $r_{i}$ be the sum of $i$-th row in matrix $\mathbf{T}$. Then $r_{i}$ demonstrates the total effects, both direct and indirect, given by factor $i$ to the other factors. Let $c_{j}$ be the sum of $\mathbf{j}$-th column in matrix $\mathbf{T}$. Then $c_{j}$ shows the total effects, both direct and indirect, received by factor $j$ from the other factors. Thus when $j=i$, the sum $\left(r_{i}+c_{i}\right)$ gives us an index representing the total effects both given and received by factor $i$. In other words, $\left(r_{i}+c_{i}\right)$ shows the degree of central role (total sum of effects given and received) that factor $i$ plays in the system. In addition, the difference $\left(r_{i}-c_{i}\right)$ shows the net effect that factor $i$ contributes to the system (degree of cause). When $\left(r_{i}-c_{i}\right)$ is positive, factor $i$ is a net causer, and when $\left(r_{i}-c_{i}\right)$ is negative, factor $i$ is a net receiver (Tzeng et al., 2007).

Step 4 : Indirect influence matrix calculation. Based on the same logic applied in obtaining relation A, this matrix is obtained in the form of Eq. (7) by expanding the sum of geometric progression:

If $S=\left[s_{i j}\right] \quad \mathrm{i}, \mathrm{j}=1,2, \ldots, \mathrm{n}$ where $S=D^{2}+D^{3}+\ldots+D^{m}$ as $m \rightarrow \infty$ then

$$
S=D^{2}+D^{3}+D^{4}+D^{5}+\ldots+D^{m}=D^{2}(I-D)^{-1} .
$$

Step 5: Setting a threshold value and preparing the impact-relation-map.

In order to explain the structural relationships among the factors while keeping the complexity of the system to a manageable level, it is necessary to set a threshold value $\mathrm{p}$ to filter out some negligible effects in matrix $\mathbf{T}$. While each factor of matrix $\mathbf{T}$ provides information on how one factor affects another, the decision-maker must set a threshold value in order to reduce the complexity of the structural relation model implicit in matrix $\mathbf{T}$. Only some factors, whose effect in matrix $\mathbf{T}$ is greater than the threshold value, should be chosen and shown in an impact-relations-map (IRM) (Tzeng et al., 2007). 


\section{Findings}

According to the method explained in step 1, the finalized relationships between indices matrix results in the form of Table 4:

\section{Table 4}

Initial direct relations matrix

\begin{tabular}{|c|c|c|c|c|c|c|c|c|c|c|}
\hline & A & B & C & D & E & $\mathrm{F}$ & G & $\mathrm{H}$ & I & $\mathrm{J}$ \\
\hline A & 0 & 3.87 & 1.46 & 2.48 & 0 & 0 & 8.63 & 0 & 2.43 & 1.63 \\
\hline B & 2.27 & 0 & 6.84 & 6.21 & 0 & 0 & 0 & 2.78 & 2.78 & 4.17 \\
\hline C & 6.38 & 2.11 & 0 & 2.42 & 0 & 2.78 & 2.83 & 0 & 1.34 & 4.32 \\
\hline D & 0 & 3.87 & 1.04 & 0 & 0 & 2.63 & 7.06 & 2.14 & 0 & 3.43 \\
\hline E & 0 & 0 & 0 & 8.56 & 0 & 0 & 4.98 & 7.32 & 8.94 & 0 \\
\hline $\mathrm{F}$ & 0 & 3.12 & 6.85 & 2.64 & 0 & 0 & 7.85 & 4.12 & 0 & 2.67 \\
\hline G & 4.96 & 5.81 & 0 & 4.18 & 0 & 0 & 0 & 0 & 0 & 0 \\
\hline $\mathrm{H}$ & 2.86 & 1.62 & 0 & 2.84 & 0 & 0 & 0 & 0 & 1.83 & 0 \\
\hline I & 0 & 1.76 & 0 & 1.48 & 1.38 & 1.12 & 7.64 & 2.32 & 0 & 1.56 \\
\hline $\mathrm{J}$ & 0 & 1.26 & 8.96 & 1.74 & 0 & 1.11 & 1.84 & 3.21 & 2.57 & 0 \\
\hline
\end{tabular}

Next, in accordance with step 2 and based on Eq. (2), the value s=44.73 is obtained, which is the sum of each row of factor E. With regard to Eq. (3), matrix D is also obtained as shown in Table 5.

\section{Table 5}

The normalized matrix of direct relationships

\begin{tabular}{c|cccccccccc}
\multicolumn{1}{c}{} & $\mathrm{A}$ & $\mathrm{B}$ & $\mathrm{C}$ & $\mathrm{D}$ & $\mathrm{E}$ & $\mathrm{F}$ & $\mathrm{G}$ & $\mathrm{H}$ & $\mathrm{I}$ & $\mathrm{J}$ \\
\cline { 2 - 11 } $\mathrm{A}$ & 0 & 0.129866 & 0.048993 & 0.083221 & 0 & 0 & 0.289597 & 0 & 0.081544 & 0.054698 \\
$\mathrm{~B}$ & 0.076174 & 0 & 0.22953 & 0.208389 & 0 & 0 & 0 & 0.093289 & 0.093289 & 0.139933 \\
$\mathrm{C}$ & 0.214094 & 0.070805 & 0 & 0.081208 & 0 & 0.093289 & 0.094966 & 0 & 0.044966 & 0.144966 \\
$\mathrm{D}$ & 0 & 0.129866 & 0.034899 & 0 & 0 & 0.088255 & 0.236913 & 0.071812 & 0 & 0.115101 \\
E & 0 & 0 & 0 & 0.287248 & 0 & 0 & 0.167114 & 0.245638 & 0.3 & 0 \\
F & 0 & 0.104698 & 0.229866 & 0.088591 & 0 & 0 & 0.263423 & 0.138255 & 0 & 0.089597 \\
G & 0.166443 & 0.194966 & 0 & 0.140268 & 0 & 0 & 0 & 0 & 0 & 0 \\
H & 0.095973 & 0.054362 & 0 & 0.095302 & 0 & 0 & 0 & 0 & 0.061409 & 0 \\
I & 0 & 0.05906 & 0 & 0.049664 & 0.046309 & 0.037584 & 0.256376 & 0.077852 & 0 & 0.052349 \\
J & 0 & 0.042282 & 0.300671 & 0.058389 & 0 & 0.037248 & 0.061745 & 0.107718 & 0.086242 & 0
\end{tabular}

In step 3 and according to Eq. (4), the direct and indirect relations degree index is obtained in the from of Table 6, which indicates the degree of total relationships identified between each pair of the LLS indices.

\section{Table 6}

Total relation matrix

\begin{tabular}{c|cccccccccc}
\multicolumn{1}{c}{} & $\mathrm{A}$ & $\mathrm{B}$ & $\mathrm{C}$ & $\mathrm{D}$ & $\mathrm{E}$ & $\mathrm{F}$ & $\mathrm{G}$ & $\mathrm{H}$ & $\mathrm{I}$ & $\mathrm{J}$ \\
\cline { 2 - 10 } $\mathrm{A}$ & 0.161164 & 0.327372 & 0.211355 & 0.286039 & 0.007351 & 0.05787 & 0.492786 & 0.093322 & 0.158739 & 0.186381 \\
$\mathrm{~B}$ & 0.25501 & 0.222768 & 0.423389 & 0.41247 & 0.009094 & 0.094928 & 0.307956 & 0.208019 & 0.196373 & 0.312692 \\
$\mathrm{C}$ & 0.358142 & 0.289792 & 0.218017 & 0.294227 & 0.006725 & 0.155935 & 0.386567 & 0.114151 & 0.145232 & 0.292152 \\
$\mathrm{D}$ & 0.16014 & 0.31593 & 0.22723 & 0.205588 & 0.003943 & 0.139799 & 0.427812 & 0.169005 & 0.085151 & 0.241656 \\
E & 0.165323 & 0.248461 & 0.146077 & 0.506863 & 0.017785 & 0.078399 & 0.480321 & 0.366529 & 0.384047 & 0.150456 \\
F & 0.229771 & 0.351242 & 0.433459 & 0.342604 & 0.005125 & 0.084777 & 0.520339 & 0.245978 & 0.110661 & 0.266975 \\
G & 0.265449 & 0.337203 & 0.149598 & 0.297133 & 0.00355 & 0.047749 & 0.20207 & 0.079796 & 0.076651 & 0.125883 \\
H & 0.148446 & 0.141627 & 0.072723 & 0.178497 & 0.00463 & 0.028785 & 0.1303 & 0.046131 & 0.099983 & 0.066839 \\
I & 0.128331 & 0.2219 & 0.126474 & 0.223531 & 0.049739 & 0.077306 & 0.415143 & 0.158927 & 0.074063 & 0.145286 \\
J & 0.179822 & 0.225576 & 0.441515 & 0.245912 & 0.007835 & 0.112183 & 0.297672 & 0.193468 & 0.169196 & 0.15262
\end{tabular}

For the appropriate analysis of the system based on the findings and values obtained in Table 6 and taking Eq. (5) and Eq. (6) into account, the order of the influence of the elements on each other is obtained from Table 7. 
Table 7

The order of the influence of the elements on each other

\begin{tabular}{cccccccc}
\hline & $\mathrm{r}$ & & \multicolumn{2}{c}{$\mathrm{c}$} & \multicolumn{2}{c}{$\mathrm{r}+\mathrm{c}$} & \multicolumn{2}{c}{$\mathrm{r}-\mathrm{c}$} \\
Order & rate & Order & rate & Order & rate & Order & rate \\
\hline $\mathrm{F}$ & 2.591 & $\mathrm{G}$ & 3.661 & $\mathrm{G}$ & 5.246 & $\mathrm{E}$ & 2.428 \\
$\mathrm{E}$ & 2.544 & $\mathrm{D}$ & 2.993 & $\mathrm{~B}$ & 5.125 & $\mathrm{~F}$ & 1.713 \\
$\mathrm{~B}$ & 2.443 & $\mathrm{~B}$ & 2.682 & $\mathrm{D}$ & 4.969 & $\mathrm{I}$ & 0.121 \\
$\mathrm{C}$ & 2.261 & $\mathrm{C}$ & 2.45 & $\mathrm{C}$ & 4.711 & $\mathrm{~J}$ & 0.085 \\
$\mathrm{~J}$ & 2.026 & $\mathrm{~A}$ & 2.052 & $\mathrm{~A}$ & 4.034 & $\mathrm{~A}$ & -0.069 \\
$\mathrm{~A}$ & 1.982 & $\mathrm{~J}$ & 1.941 & $\mathrm{~J}$ & 3.967 & $\mathrm{C}$ & -0.189 \\
$\mathrm{D}$ & 1.976 & $\mathrm{H}$ & 1.675 & $\mathrm{~F}$ & 3.469 & $\mathrm{~B}$ & -0.239 \\
$\mathrm{I}$ & 1.621 & $\mathrm{I}$ & 1.5 & $\mathrm{I}$ & 3.121 & $\mathrm{H}$ & -0.757 \\
$\mathrm{G}$ & 1.585 & $\mathrm{~F}$ & 0.878 & $\mathrm{E}$ & 2.66 & $\mathrm{D}$ & -1.017 \\
$\mathrm{H}$ & 0.918 & $\mathrm{E}$ & 0.116 & $\mathrm{H}$ & 2.593 & $\mathrm{G}$ & -2.076 \\
\hline
\end{tabular}

As shown in Table 7, the results of the analysis of the system relationships in terms of the influential and influenced elements show that: based on the order of the elements in column r, the 4 most influential system indices with an effect range $>2$ respectively were: communication channels, reward systems, trust, openness in communication and face to face interactions. Moreover, the elements most affected by the other elements of the system were ranked as follows: knowledge sharing self-efficiency, collaboration, trust, openness in communication and perception. In step 4, with regard to Eq. (7), the indirect influence matrix is obtained as shown in Table 8.

\section{Table 8}

Indirect influence matrix

\begin{tabular}{c|cccccccccc}
\multicolumn{1}{c}{} & $\mathrm{A}$ & $\mathrm{B}$ & $\mathrm{C}$ & $\mathrm{D}$ & $\mathrm{E}$ & $\mathrm{F}$ & $\mathrm{G}$ & $\mathrm{H}$ & $\mathrm{I}$ & $\mathrm{J}$ \\
\cline { 2 - 11 } $\mathrm{A}$ & 0.161164 & 0.197506 & 0.162362 & 0.202818 & 0.007351 & 0.05787 & 0.203189 & 0.093322 & 0.077196 & 0.131683 \\
B & 0.178836 & 0.222768 & 0.193859 & 0.204081 & 0.009094 & 0.094928 & 0.307956 & 0.114731 & 0.103084 & 0.172759 \\
$\mathrm{C}$ & 0.144048 & 0.218986 & 0.218017 & 0.213019 & 0.006725 & 0.062646 & 0.291601 & 0.114151 & 0.100265 & 0.147186 \\
D & 0.16014 & 0.186064 & 0.19233 & 0.205588 & 0.003943 & 0.051544 & 0.190899 & 0.097193 & 0.085151 & 0.126556 \\
E & 0.165323 & 0.248461 & 0.146077 & 0.219615 & 0.017785 & 0.078399 & 0.313207 & 0.120891 & 0.084047 & 0.150456 \\
F & 0.229771 & 0.246544 & 0.203593 & 0.254013 & 0.005125 & 0.084777 & 0.256916 & 0.107723 & 0.110661 & 0.177378 \\
G & 0.099006 & 0.142236 & 0.149598 & 0.156865 & 0.00355 & 0.047749 & 0.20207 & 0.079796 & 0.076651 & 0.125883 \\
H & 0.052473 & 0.087265 & 0.072723 & 0.083195 & 0.00463 & 0.028785 & 0.1303 & 0.046131 & 0.038573 & 0.066839 \\
I & 0.128331 & 0.162839 & 0.126474 & 0.173867 & 0.00343 & 0.039722 & 0.158767 & 0.081074 & 0.074063 & 0.092937 \\
J & 0.179822 & 0.183295 & 0.140844 & 0.187523 & 0.007835 & 0.074935 & 0.235927 & 0.08575 & 0.082954 & 0.15262
\end{tabular}

In step 5, based on the results of Table 7, the impact-relation-map has resulted in the form of Fig. 2. As is shown in the figure, the indices above the axis zero are the influential factors and those below the axis zero are the influenced factors of the system.

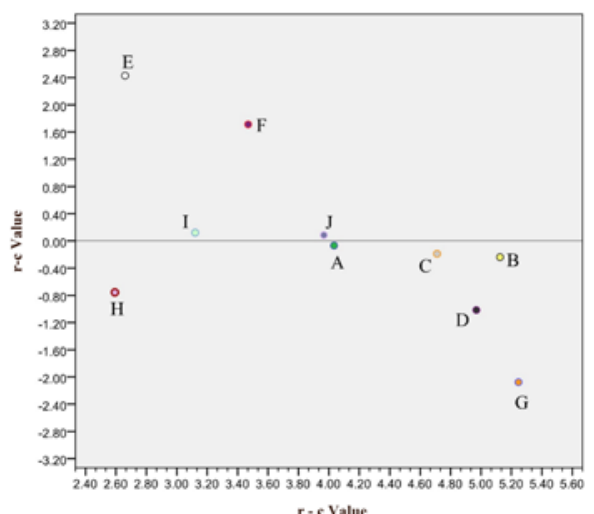

Fig. 2. The impact-relations-map (causal diagram)

For the analysis of Fig. 2 with regard to the primary relationships identified in Table 4, the manner of the direct relations of index $\mathrm{E}$ (with the characteristic of having the most influence on other indices) 
and index $\mathrm{G}$ (with the highest rate of receiving influence from other indices) has been specified as an example (See Fig. 3).
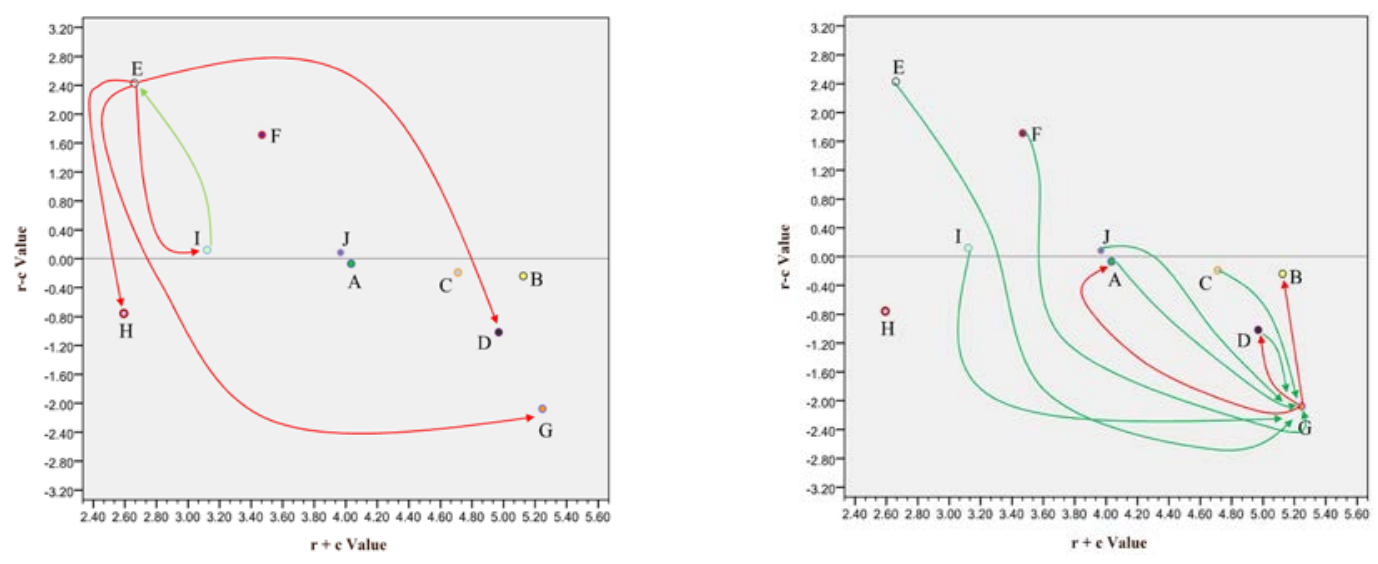

Fig. 3. The manner of direct relationships between index $G$ and other indices (left figure), and between index $\mathrm{E}$ and other indices (right figure).

With regard to Fig. 3 (left figure), factor $\mathrm{E}$ has been identified with the highest rate of causal effect on the other indices of the impact-relation-map, which shows the bigger number of the direct effects it exerts on the other indices than the number of the effects it receives from the other indices (the manner of these relationship is based on the finalized relationship between indices matrix). Likewise, with regard to Fig. 3 (left figure), factor $G$ has received the most direct influence from the other factors, and all of its causal relationships with the other indices of the system lie at the influence receiving level (below axis zero). Also, since factor $\mathrm{G}$ with the characteristic of receiving effect has the greatest degree of growth along axis $(\mathrm{r}-\mathrm{c})$, the system under study in the present research is a system of predominant effect-receiving characteristic.

Ultimately, the histograms of the direct and indirect influence and being influenced of the indices have been obtained in Fig. 4. The histograms provide complete information on the rate of the sum of the direct and indirect influence and being influenced of the system components. For instance, regarding the mentioned histograms and the results obtained from Fig. 7, the obtained results so far indicate that the indices of trust (B) and openness in communication (C) are both parts of the most influential and the most influenced elements. This is because these two indices have a considerable rate of exerting influence on or receiving influence from the other indices of the system.

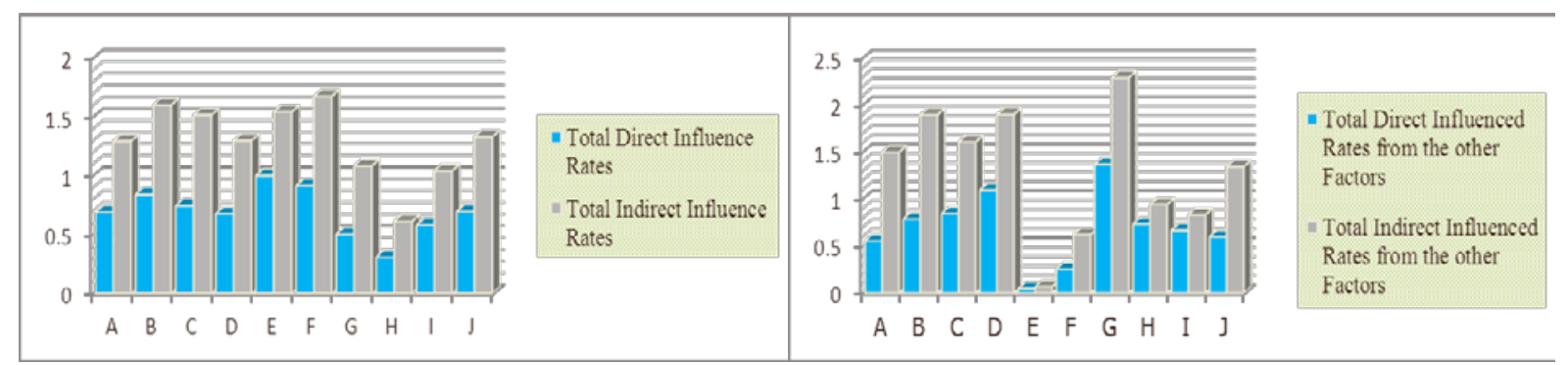

Fig. 4. Histograms of direct and indirect influence / influenced rates of the indices

According to Fig. 4, the direct and indirect rates of the factors have been obtained from the sum of the rows and columns of Table 8. Also, with regard to the two histograms in Fig. 4, the numerical rate of the indirect influence/ effect in all of the factors is greater than the rate of their direct influence/ effect. Furthermore, regarding the influence receiving histogram, factor $G$ has been identified to have the highest rate of being influenced by the other factors. Fig. 4 represents complete information about the rate of influence and effect of each of the research components separately. In fact, these histograms give a vaster amount of information than the previous table concerning the degree of the internal 
relationships among the factors of KS system by means of the numerical indices of influencing or being influenced in the form of a visual summary of the previously obtained information, which can be used in system analyses. For example, in Table 7, the order of exerting or receiving influence of the factors of the system has been specified; however, with regard to the information given in Fig. 4, in addition to making comparisons and ranking the components in terms of their direct and indirect influence/ influenced rates, it is possible to obtain an order of the rates of the mentioned indices for each component separately so that by using them, a better view of the system under study could be achieved. For instance, the following relation applies to component $\mathrm{H}$ :

Total direct influence rate for $(\mathrm{H})<$ Total indirect influence rate for $(\mathrm{H})<$ Total direct affected rate from the other ones for $(\mathrm{H})<$ Total indirect affected rate from the other ones for $(\mathrm{H})$

The above relation indicates the main characteristic of component $\mathrm{H}, i$. e., its indirect affected rate by other indices. In addition, it reveals that the numerical rate for the total indirect influence index has been specified lower for component $\mathrm{H}$ than the other four indices.

\section{Discussion and Conclusion}

The systemic approach to the concept of KM and KSS requires that initially, in terms of the identified components of the system and the resulting feedbacks, a dynamic approach be adopted to improve the relevant processes. To increase system efficiency and effectiveness, an understanding of the nature and the rate of the effect of the elements and indices on each other has to be developed. DEMATEL technique contributes to determining the intensity of indirect relationships of the system, and enhances the analysis of potential intensity of both direct and indirect relationships obtained from the experts' responses. On the basis of the obtained information (Table 7, Figs. 2-4), the system under study could be analyzed as follows:

The marked indices with the high level of effectiveness (see Table 7 column r's indices order) are the basic elements and indices of the system and act as the system cornerstone, the enrichment of which leads to a set of changes in the course of the whole system improvement. E (reward systems) and F (communication channels) are the most influential indices, the strengthening of which indirectly reinforces the whole system. Thus, considering the foregoing points, we can conclude that the most productive decision for reinforcing KSS in LLS were based on the positive influence on these two components ( $\mathrm{E} \& \mathrm{~F}$ ). Moreover, the results of the study indicate that the knowledge sharing selfefficiency and Trust systems indexes were the most influential and influenced ones (Fig. 4 and Table 7) in the system under study. The innovative feature of the present research is that it has presented the direct and indirect internal relationships indices among the components of the system in the form of histograms. The histograms render the information pertinent to the nature and rate of the indices under study in visual from and capable of being compared within the framework of the system indices. Ultimately, the final results obtained based on the systemic analysis of the components and the findings of the present research methodology indicate that to create an effective change in the knowledge sharing system, the priority in creating positive change need to be given to the performance of the components that have been identified as the ones influencing the other components. Studying the nature of the internal relationships among the indices of knowledge sharing in LL systems showed that to create a positive as well as optimal effect on knowledge sharing processes, the first priority should be given to the updating and reinforcing "Communication Channels", and "reward systems and processes" should be reinforced as the second priority in line with the reinforcement of the purposeful process of knowledge sharing system.

\section{References}

Abecker, A., Bernardi, A., Hinkelmann, K., Kühn, O., \& Sintek, M. (1997, March). Towards a wellfounded technology for organizational memories. InProceedings of the AAAI Spring Symposium on Artificial Intelligence in Knowledge Management (pp. 24-26). 
Babalhavaeii, F., \& Kermani, Z. J. (2011). Knowledge sharing behaviour influences: a case of Library and Information Science faculties in Iran.Malaysian Journal of Library \& Information Science, 16(1), 1-14.

Becerra-Fernandez, I., \& Sabherwal, R. (2010). Knowledge management: systems and processes. ME Sharpe.

Bellifemine, F., Caire, G., Poggi, A., \& Rimassa, G. (2008). JADE: A software framework for developing multi-agent applications. Lessons learned. Information and Software Technology, 50(1), 10-21.

Dignum, M. V. (2008). A knowledge sharing model for peer collaboration in the non-life insurance domain.

Gabus, A., \& Fontela, E. (1973). Perceptions of the world problematique: Communication procedure, communicating with those bearing collective responsibility. Battelle Geneva Research Centre, Geneva, Switzerland.

Gruber, H. G., \& Duxbury, L. (2000). Does organizational culture affect the sharing of knowledge: The case of a department in a high-technology company. In Administrative Sciences Association of Canada, Annual Conference, 21(25), 101-101.

Hedlund, G., \& Nonaka, I. (1993). Models of knowledge management in the West and Japan, Oxford.

Hsu, M. H., Ju, T. L., Yen, C. H., \& Chang, C. M. (2007). Knowledge sharing behavior in virtual communities: The relationship between trust, self-efficacy, and outcome expectations. International Journal of Human-Computer Studies,65(2), 153-169.

Hung, Y. C., Huang, S. M., Lin, Q. P., \& -Tsai, M. L. (2005). Critical factors in adopting a knowledge management system for the pharmaceutical industry.Industrial Management \& Data Systems, 105(2), 164-183.

Islam, Z. M., Hasan, I., Ahmed, S. U., \& Ahmed, S. M. (2011). Organizational culture and knowledge sharing: Empirical evidence from service organizations.African Journal of Business Management, 5(14), 5900-5909.

Seonghee, K., \& Boryung, J. (2008). An analysis of faculty perceptions: Attitudes toward knowledge sharing and collaboration in an academic institution. Library \& Information Science Research, 30(4), 282-290.

Lin, M. J. J., Hung, S. W., \& Chen, C. J. (2009). Fostering the determinants of knowledge sharing in professional virtual communities. Computers in Human Behavior, 25(4), 929-939.

Lin, H. F. (2007). Knowledge sharing and firm innovation capability: an empirical study. International Journal of Manpower, 28(3/4), 315-332.

Manian, A., Mira, S. A., \& Karimi, E. (2012). Analysis of Effective Factors on Knowledge Sharing Among E-Learning Students (Case Study: Tehran University E-learning Campus). Journal of Information processing and Management, 27(1), 47-65.

McDermott, R. (2000). Why information technology inspired but cannot deliver knowledge management. Knowledge and communities, 41(4), 21-35.

Riege, A. (2005). Three-dozen knowledge-sharing barriers managers must consider. Journal of knowledge management, 9(3), 18-35.

Sveiby, K. E., \& Simons, R. (2002). Collaborative climate and effectiveness of knowledge work-an empirical study. Journal of Knowledqe Manaqement, 6(5), 420-433.

Szulanski, G. (1996). Exploring internal stickiness: Impediments to the transfer of best practice within the firm. Strateqic manaqement journal, 17(S2), 27-43.

Tzeng, G. H., Chiang, C. H., \& Li, C. W. (2007). Evaluating intertwined effects in e-learning programs: A novel hybrid MCDM model based on factor analysis and DEMATEL. Expert systems with Applications, 32(4), 1028-1044.

Wang, S., \& Noe, R. A. (2010). Knowledge sharing: A review and directions for future research. Human Resource Management Review, 20(2), 115-131.

Weber, R., Aha, D. W., \& Becerra-Fernandez, I. (2001). Intelligent lessons learned systems. Expert systems with applications, 20(1), 17-34.

Willem, A., \& Buelens, M. (2009). Knowledge sharing in inter-unit cooperative episodes: The impact of organizational structure dimensions. International Journal of Information Management, 29(2), 151-160.

Yang, J. T. (2010). Antecedents and consequences of knowledge sharing in international tourist hotels. International Journal of Hospitality Management,29(1), 42-52. 